\title{
Resistance of Pre- and Post-epidemic Strains of Agaricus bisporus to Trichoderma aggressivum f. aggressivum
}

\author{
X. Chen, M. D. Ospina-Giraldo, V. Wilkinson, D. J. Royse, and C. P. Romaine, 210 Buckhout Laboratory, De- \\ partment of Plant Pathology, Pennsylvania State University, University Park 16802
}

\begin{abstract}
Chen, X., Ospina-Giraldo, M. D., Wilkinson, V., Royse, D. J., and Romaine, C. P. 2003. Resistance of pre- and post-epidemic strains of Agaricus bisporus to Trichoderma aggressivum $\mathrm{f}$. aggressivum. Plant Dis. 87:1457-1461.

Since the early 1990s, the epidemic of green mold on the cultivated mushroom Agaricus bisporus in North America has been caused by Trichoderma aggressivum f. aggressivum. The findings of earlier research suggested that the microevolutionary emergence of $T$. aggressivum f. aggressivum coincided with the onset of the epidemic. This hypothesis was tested further by determining the disease susceptibility of mushroom strains grown widely before the epidemic manifested. The results of complementary methods of analysis, which entailed a grain protection assay and cropping trials, established that two pre-epidemic strains were more susceptible to green mold than three post-epidemic strains being cultivated at the time of the epidemic. Thus, if T. aggressivum f. aggressivum had been present within cultivated mushrooms prior to the epidemic, it should have been detected. It still appears to be true that $T$. aggressivum f. aggressivum emerged during the 1990s in a manner that remains unclear.
\end{abstract}

Of all the edible mushroom species, Agaricus bisporus (Lange) Imbach. (button mushroom) ranks first worldwide in commercial importance, being grown principally in North America, Europe, the Far East, and Australasia (3). In the United States, Agaricus mushrooms are cultivated in 23 states with a total production in 2001 to 2002 of 838 million pounds (13). At a crop value of $\$ 875$ million, mushrooms rank fourth among all vegetables, after potatoes, tomatoes, and lettuce (6).

Sinden and Hauser (25) were the first to formally recognize Trichoderma as the pathogen of green mold disease on cultivated $A$. bisporus. Green mold had long been regarded as a minor nuisance, because typically it was confined to small areas in the production bed, and only occurred periodically in association with substandard compost (10). In practice, the disease could be effectively controlled by remedying the composting problem, thorough hygiene, and chemical intervention.

In 1985, widespread outbreaks of Trichoderma green mold occurred at commercial mushroom operations in Northern Ireland $(23,26)$ and, subsequently, throughout Europe and North America $(2,5,12,23)$. These episodes of the disease were more destructive and difficult to manage by

Corresponding author: C. P. Romaine

E-mail: cpr2@psu.edu

Accepted for publication 12 July 2003.

Publication no. D-2003-0930-01R

(C) 2003 The American Phytopathological Society conventional means than those of the past. The pathogen appeared as a white-colored mold rampantly invading the compost and peat overlay (casing), and eventually developed a dark green color with the formation of profuse masses of spores. Unlike other Trichoderma green molds on A. bisporus (25), the pathogen flourished in high-quality compost and caused a near complete cessation in formation of mushrooms (7).

Recent pandemics of green mold occurring on $A$. bisporus $(2,5,12,14,23)$ are attributed to newly described species of Trichoderma. T. aggressivum f. aggressivum Samuels \& W. Gam and T. aggressivum f. europaeum Samuels \& W. Gam currently cause green mold in North America and Europe, respectively (21). These biological forms can be distinguished from each other and from other Trichoderma species by morphological, cultural, and molecular characters $(2,4,5,12,14,18,21$, 23,24).

For almost two decades, an estimated $90 \%$ of agaric mushrooms cultivated in North America and Europe have represented the U1 off-white hybrid strain, while the others are brown strains marketed primarily as the 'Portabella'. First introduced in the mid 1980s, U1 and the less popular U3 white hybrid (8) rapidly supplanted the white, off-white, and cream strains that were the standards in the industry (28).

Although there is little doubt that the emergence of new genotypes of the fungal pathogen coincided with the development of the green mold pandemics, there remains the question of whether or not the near-global monoculture of U1 mushrooms at the time might have been a confounding factor. An evaluation of disease resistance has not been carried out on strains prevailing in the industry prior to introduction of the hybrids and before the onset of the green mold epidemic. In this study, we have used a combination of an in vitro grain protection assay and yield response in cropping trials to compare the reactions of pre- and post-epidemic mushroom strains to green mold disease caused by $T$. aggressivum f. aggressivum.

\section{MATERIALS AND METHODS}

Fungal cultures. The five commercial strains of $A$. bisporus used in this study are maintained in the Pennsylvania State University Mushroom Culture Collection. The strains included a white (310) and a cream (324), both of which were cultivated widely during the 1970s in North America and Europe (pre-epidemic), and the white (U3) and off-white (U1) hybrids and a brown (344), which were cultivated during and following the green mold epidemic (post-epidemic). Isolate 114 of T. aggressivum $\mathrm{f}$. aggressivum, which was associated with an overt outbreak of green mold disease on a commercial mushroom operation in Pennsylvania (5), was used exclusively in this investigation. Fungal stock cultures were maintained at room temperature on potato dextrose yeast agar (PDYA; broth from $250 \mathrm{~g}$ of boiled potatoes, $10 \mathrm{~g}$ of dextrose, $1.5 \mathrm{~g}$ of yeast extract, and $15 \mathrm{~g}$ of agar per liter of water).

Inoculum. A mycelial agar block from a stock culture of $T$. aggressivum f. aggressivum was transferred to a 15 -cm-diameter petri dish of PDYA. Cultures were grown at room temperature $\left(22 \pm 2^{\circ} \mathrm{C}\right)$ for 10 days, at which time the spores were liberated by gentle agitation with a sterile wire loop in the presence of $10 \mathrm{ml}$ of sterile water and then passed through a piece of filter paper. The concentration of spores was determined using a hemacytometer (Haussen Hy-lite Ultra Plane, Improved Neubauer, Philadelphia, PA), and the suspension was diluted with sterile water to inoculum levels of $1 \times 10^{3}, 1 \times 10^{4}$, and 1 $\times 10^{5}$ spores per $\mathrm{ml}$.

Grain protection assay. An in vitro assay in which spawns were challengeinoculated with $T$. aggressivum f. aggressivum was done in 250-ml Erlenmeyer flasks, each containing $40 \mathrm{~g}$ of rye grain, $0.8 \mathrm{~g}$ of $\mathrm{CaCO}_{3}, 0.4 \mathrm{~g}$ of $\mathrm{CaSO}_{4}$, and $61 \mathrm{ml}$ 
of distilled water. Flasks were sealed with cotton plugs and autoclaved for $20 \mathrm{~min}$ at $121^{\circ} \mathrm{C}$. When the grain had cooled, three 5mm-diameter mycelial agar plugs were transferred from a stock culture of $A$. bisporus to each flask. Flasks were incubated at room temperature, with brief manual shakings at 5- to 7-day intervals, until the grain had become completely colonized by mycelium ( 3 to 4 weeks). At this time, 1 $\mathrm{ml}$ of an aqueous suspension containing 1 $\times 10^{3}, 1 \times 10^{4}$, or $1 \times 10^{5}$ spores of T. aggressivum f. aggressivum was added to a flask. Flasks were shaken briefly to distribute the inoculum throughout the spawn. Control treatments consisted of the sterilized grain-calcium mixture alone inoculated with water containing 0 or $1 \times 10^{3}$ spores. Flasks were incubated at room temperature and observed daily for the development of green mold. After 2 weeks, the spawns were visually assessed for the extent of surface area showing green mold using the following rating scale: $0 \%, 1$ to $25 \%, 26$ to $50 \%, 51$ to $75 \%$, and 76 to $100 \%$. Three replicate flasks were used for each treatment in an experiment, and experiments were conducted three times.

Cropping trials. Three production trials were carried out at the Mushroom Research Center of Pennsylvania State University, University Park, essentially as outlined by Romaine and Schlagnhaufer (19). A deviation from the protocol in- cluded the application using an atomizer (model 15, DeVilbiss Co., Somerset, PA) of $1 \mathrm{ml}$ of water containing 0 (noninoculated control), $1 \times 10^{3}$, or $1 \times 10^{4}$ spores of T. aggressivum f. aggressivum to $150 \mathrm{-g}$ allotments of mushroom spawn. Each 150g quantity of spawn was admixed with $22.7 \mathrm{~kg}$ of compost, which then was packed into a $0.6 \times 0.6 \times 0.15 \mathrm{~m}$ wooden tray. Where indicated, $454 \mathrm{~g}$ of the timereleased supplement, Spawn Mate IISE (Spawn Mate Co., Inc., Capitola, CA), was also mixed with the spawn in the compost.

Three (trials I and II) or four (trial III) trays for each treatment were arranged in a completely randomized block design in the production room. During cropping, the weight of mushrooms harvested from each tray was recorded daily for 28 days. Data were analyzed using the SAS program JMP (22). The standard least-squares model procedure was used to perform a two-way analysis of variance with interaction. Treatment means were separated using Tukey-Kramer honestly significant difference (HSD) test at $P=0.05$.

\section{RESULTS}

Grain protection assay. The in vitro assay was designed to determine if mushroom strains differed in their ability to protect the rye grain substrate from colonization by $T$. aggressivum f. aggressivum. Of the various treatments, the sterile rye
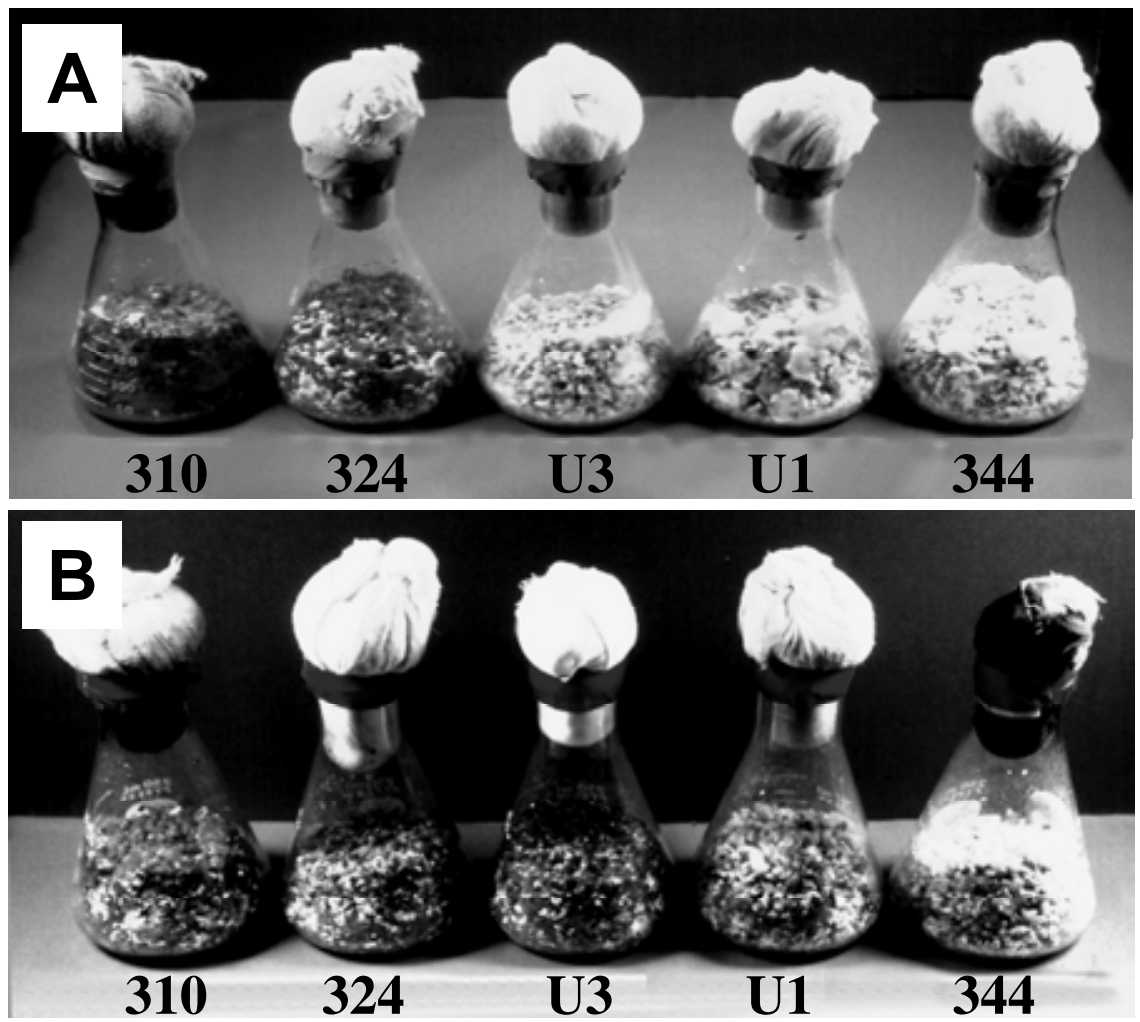

Fig. 1. Evaluation of mushroom strains using the in vitro grain protection assay for resistance to Trichoderma aggressivum f. aggressivum. Spawns prepared from the pre-epidemic white (310) and cream (324) strains and post-epidemic white (U3), off-white (U1), and brown (344) strains are shown. A and $\mathbf{B}$ refer to inoculum levels of $1 \times 10^{3}$ and $1 \times 10^{5}$ spores, respectively. Areas colonized by green mold appear darkly shaded against the white-colored growth of Agaricus bisporus. Spawns are shown at 2 weeks postinoculation. grain substrate control, which was not colonized by $A$. bisporus, supported the highest rate of $T$. aggressivum f. aggressivum invasion, with 86 to $100 \%$ surface colonization within 5 days of inoculation. By comparison, green mold was never observed in the substrate control treatment receiving water alone.

The development of green mold on sterile rye grain substrate colonized by $A$. bisporus was influenced by the mushroom strain and, in some cases, the concentration of inoculum (Fig. 1). Of the strains tested, the pre-epidemic white and cream were most susceptible to T. aggressivum f. aggressivum. Irrespective of inoculum level, and at 7 to 10 days postinoculation, $T$. aggressivum f. aggressivum colonized 86 to $100 \%$ of the surface areas of these spawns. Spawns prepared from the postepidemic white, off-white, and brown strains displayed a higher resistance than the pre-epidemic strains. At 2 weeks postinoculation, the white and off-white strains developed green mold to similar extents, with ratings of $0 \%, 1$ to $50 \%$, and 51 to $100 \%$ colonization at inoculum levels of $1 \times 10^{3}, 1 \times 10^{4}$, and $1 \times 10^{5}$ spores per $\mathrm{ml}$, respectively. The brown strain was most resistant, with 1 to $25 \%$ colonization by green mold only at the highest level of inoculum.

Cropping trials. The pre-epidemic white strain and post-epidemic off-white and brown strains, which represented the range of resistance displayed in the grain assay, were evaluated in three cropping trials for yield response under disease pressure. Trials I and II were identical experiments conducted within a 3-month period. An $F$ test showed that results of the two trials were not significantly different $(P=$ 0.101 ); therefore, the data were combined.

Of the three strains evaluated, T. aggressivum f. aggressivum markedly inhibited the vegetative growth of only the preepidemic white strain. At inoculum levels of $1 \times 10^{3}$ and $1 \times 10^{4}$ spores, green mold grew so extensively in the compost that it largely limited the invasion of the compost and peat-based casing overlay by this strain. In contrast, colonization of the compost by the post-epidemic off-white strain was not impeded by $T$. aggressivum f. aggressivum, but small areas of green mold were observed at the highest inoculum level and toward the end of the spawn growth period. In this case, mycelium of the off-white strain ramified the upper casing layer, but extensive areas of green mold appeared later in the cropping cycle. With the post-epidemic brown strain, visible areas of green mold were not observed in the compost during the spawn run period or in the casing layer throughout the cropping cycle.

At the inoculum level of $1 \times 10^{3}$ spores, the yield of mushrooms for the preepidemic white strain was reduced by approximately $90 \%$, whereas the productiv- 
ities of the post-epidemic off-white and brown strains were not significantly affected (Table 1). At the higher level of inoculum $\left(1 \times 10^{4}\right.$ spores $)$, however, significant reductions in productivity were observed for the white and off-white strains, but not the brown. The mean yield losses for white, off-white, and brown strains were approximately 99, 65, and 26\%, respectively. Overall, the post-epidemic brown strain showed the highest resistance, the post-epidemic off-white strain a moderate resistance, and the pre-epidemic white strain was most susceptible.

In cropping trial III, the mushroom strains used in the first two trials were evaluated for disease susceptibility at a single inoculum level $\left(1 \times 10^{4}\right.$ spores $)$ and two levels of compost nutrition (nonsupplemented or supplemented with Spawn Mate II SE). In this trial, the characteristics of the three mushroom strains and T. aggressivum f. aggressivum during vegetative colonization of the nonsupplemented compost and the casing layer mirrored what was observed in the first two trials. In the presence of the nitrogenous supplement, green mold appeared earlier and grew more extensively in the compost and casing with the white and off-white strains when compared with that in the nonsupplemented compost. This was not the case for the brown strain, where addition of the supplement failed to produce visible areas of green mold.

The impact of T. aggressivum f. aggressivum on mushroom production in trial III was lower than that observed in the earlier trials, but the overall trend for an effect on yield by mushroom strain was identical. In nonsupplemented compost, T. aggressivum f. aggressivum significantly reduced the yield of the pre-epidemic white strain by $73 \%$ and the post-epidemic off-white strain by $32 \%$, but it did not significantly affect the productivity of the post-epidemic brown strain (Table 2). Supplementation in the absence of the disease increased significantly the yield of mushrooms for the white and off-white strains, but not the brown strain. However, the addition of supplement to the compost did not mitigate crop loss caused by the disease (Fig. 2). Mushroom production for the pre-epidemic white and post-epidemic off-white strains in the supplemented compost was significantly reduced, by 97 and $51 \%$, respectively. On a percent yield loss basis, use of the supplement appeared to exacerbate green mold disease with these two strains, although the actual yields $\left(\mathrm{kg} / \mathrm{m}^{2}\right)$ were comparable to those from nonsupplemented compost. This was, in part, due to significantly higher yields obtained in the absence of the pathogen from the supplemented compost relative to the nonsupplemented compost. For the brown strain, mushroom production with disease pressure was comparable for the nonsupplemented and supplemented composts.

\section{DISCUSSION}

The green mold epidemic on cultivated A. bisporus in North America is purportedly the consequence of the de novo emergence of a novel form of the pathogen $T$. aggressivum $\mathrm{f}$. aggressivum, because this genotype was not represented by a collection of Trichoderma isolates from cultivated mushrooms dating back to the $1950 \mathrm{~s}$ (5). Still, we sought to determine if the dramatic transition of the worldwide mushroom industry from the growing of diverse genotypes to a virtual monoculture of the U1 off-white hybrid strain might have been a contributing factor. Experimental data $(1,16)$, as well as observations by growers, suggested that brown mushrooms were more resistant than hybrid mushrooms to green mold. The results of the present study confirm this observation. Moreover, our evidence suggests $T$. aggressivum f. aggressivum could have gained a foothold in cultivated mushrooms long before the introduction and widespread use of the hybrid strains, because the popular white and cream predecessors in the industry (28) were highly susceptible to green mold disease.
That $T$. aggressivum f. aggressivum did not manifest earlier points to the recent emergence of this unique genotype as the precipitating factor for the North American epidemic.

In the commercial production of mushrooms, the application of benzimidazole fungicides (i.e., benomyl, carbendazim, thiophanate methyl) to the grain spawn provides highly effective control of green mold disease caused by $T$. aggressivum $\mathrm{f}$. aggressivum and T. aggressivum f. europaeum $(9,17,20)$. Evidently, the carbohydrate reserve of the grain is a critical nutrient source that allows the pathogen to grow luxuriantly in the compost, colonizing expansive areas of the production bed, with a corresponding reduction in mushroom yield (7). Treating spawn with a fungicide allows the benomyl-tolerant $A$. bisporus to utilize the carbohydrate to the exclusion of the pathogen. The addition of supplements to the compost was found to exacerbate green mold (15), a trend we observed in one study, but which was not supported statistically.

We questioned if differences in disease resistance among mushroom strains reflect

Table 1. Effect of Trichoderma green mold on the yield of pre- and post-epidemic strains of Agaricus bisporus (trials I and II) ${ }^{\mathrm{w}}$

\begin{tabular}{|c|c|c|c|}
\hline $\begin{array}{l}\text { Mushroom } \\
\text { strain }\end{array}$ & $\begin{array}{c}\text { Inoculum } \\
\text { level }^{\mathrm{x}}\end{array}$ & $\begin{array}{c}\text { Yield } \\
\left(\mathbf{k g} / \mathbf{m}^{2}\right)^{\mathbf{y}}\end{array}$ & $\begin{array}{c}\text { Percent yield } \\
\text { change }^{\mathrm{z}}\end{array}$ \\
\hline \multirow{3}{*}{ Pre-epidemic white } & 0 & $10.15 \mathrm{ab}$ & \\
\hline & $1 \times 10^{3}$ & $0.96 \mathrm{de}$ & -90.5 \\
\hline & $1 \times 10^{4}$ & $0.06 \mathrm{e}$ & -99.4 \\
\hline \multirow{3}{*}{ Post-epidemic off-white } & 0 & $10.94 \mathrm{a}$ & \\
\hline & $1 \times 10^{3}$ & $8.68 \mathrm{ab}$ & -20.7 \\
\hline & $1 \times 10^{4}$ & $3.79 \mathrm{~cd}$ & -65.4 \\
\hline \multirow{3}{*}{ Post-epidemic brown } & 0 & $9.08 \mathrm{ab}$ & $\ldots$ \\
\hline & $1 \times 10^{3}$ & $9.96 \mathrm{ab}$ & +9.7 \\
\hline & $1 \times 10^{4}$ & $6.70 \mathrm{bc}$ & -26.2 \\
\hline
\end{tabular}

${ }^{\mathrm{w}}$ Data represent mean values for two experiments with three replicate trays per treatment in each experiment.

${ }^{\mathrm{x}}$ Number of spores of Trichoderma aggressivum f. aggressivum applied to $150 \mathrm{~g}$ of mushroom spawn for each tray of compost.

y Determined after 28 days of mushroom production. Means followed by the same letter are not significantly different according to the Tukey-Kramer HSD test at $P=0.05$.

${ }^{\mathrm{z}}$ Percent difference in mushroom production between inoculated and noninoculated treatments.

Table 2. Effect of Trichoderma green mold on the yield of pre- and post-epidemic strains of Agaricus bisporus in supplemented and nonsupplemented compost on yield (trial III) ${ }^{\mathrm{v}}$

\begin{tabular}{|c|c|c|c|c|c|}
\hline \multirow[b]{2}{*}{$\begin{array}{l}\text { Mushroom } \\
\text { strain }\end{array}$} & \multirow[b]{2}{*}{$\begin{array}{c}\begin{array}{c}\text { Inoculum } \\
\text { level }^{w}\end{array} \\
\end{array}$} & \multicolumn{2}{|c|}{ Nonsupplemented } & \multicolumn{2}{|c|}{ Supplemented $^{\mathrm{x}}$} \\
\hline & & $\begin{array}{c}\text { Yield } \\
\left(\mathrm{kg} / \mathrm{m}^{2}\right)^{\mathrm{y}}\end{array}$ & $\begin{array}{l}\% \text { yield } \\
\text { change }^{\mathrm{z}}\end{array}$ & $\begin{array}{c}\text { Yield } \\
\left(\mathbf{k g} / \mathbf{m}^{2}\right)\end{array}$ & $\begin{array}{l}\% \text { yield } \\
\text { change }\end{array}$ \\
\hline $\begin{array}{l}\text { Pre-epidemic } \\
\text { white }\end{array}$ & $\begin{array}{c}0 \\
1 \times 10^{4}\end{array}$ & $\begin{array}{r}12.35 \mathrm{~b} \\
3.31 \mathrm{e}\end{array}$ & -73.2 & $\begin{array}{r}16.41 \mathrm{a} \\
0.55 \mathrm{e}\end{array}$ & -96.7 \\
\hline $\begin{array}{l}\text { Post-epidemic } \\
\text { off-white }\end{array}$ & $\begin{array}{c}0 \\
1 \times 10^{4}\end{array}$ & $\begin{array}{l}12.08 \mathrm{~b} \\
8.26 \mathrm{~cd}\end{array}$ & $\begin{array}{c}\ldots \\
-31.6\end{array}$ & $\begin{array}{l}17.24 \mathrm{a} \\
8.41 \mathrm{~cd}\end{array}$ & $\begin{array}{c}\ldots \\
-51.2\end{array}$ \\
\hline $\begin{array}{l}\text { Post-epidemic } \\
\text { brown }\end{array}$ & $\begin{array}{c}0 \\
1 \times 10^{4}\end{array}$ & $\begin{array}{l}9.88 \mathrm{bcd} \\
7.76 \mathrm{~d}\end{array}$ & $\begin{array}{c}\ldots \\
-21.5\end{array}$ & $\begin{array}{l}12.03 \mathrm{~b} \\
11.38 \mathrm{bc}\end{array}$ & $\begin{array}{l}\ldots \\
-5.4\end{array}$ \\
\hline
\end{tabular}

${ }^{\mathrm{v}}$ Data represent mean values for one experiment with four replicate trays per treatment.

${ }^{\mathrm{w}}$ Number of spores of Trichoderma aggressivum f. aggressivum applied to $150 \mathrm{~g}$ of mushroom spawn for each tray of compost.

${ }^{\mathrm{x}}$ At spawning, $454 \mathrm{~g}$ of time-released supplement SpawnMate IISE was mixed with compost in each tray.

${ }^{y}$ Determined after 28 days of mushroom production. Means followed by the same letter are not significantly different according to the Tukey-Kramer HSD test at $P=0.05$.

${ }^{z}$ Percent difference in mushroom production between inoculated and noninoculated treatments. 


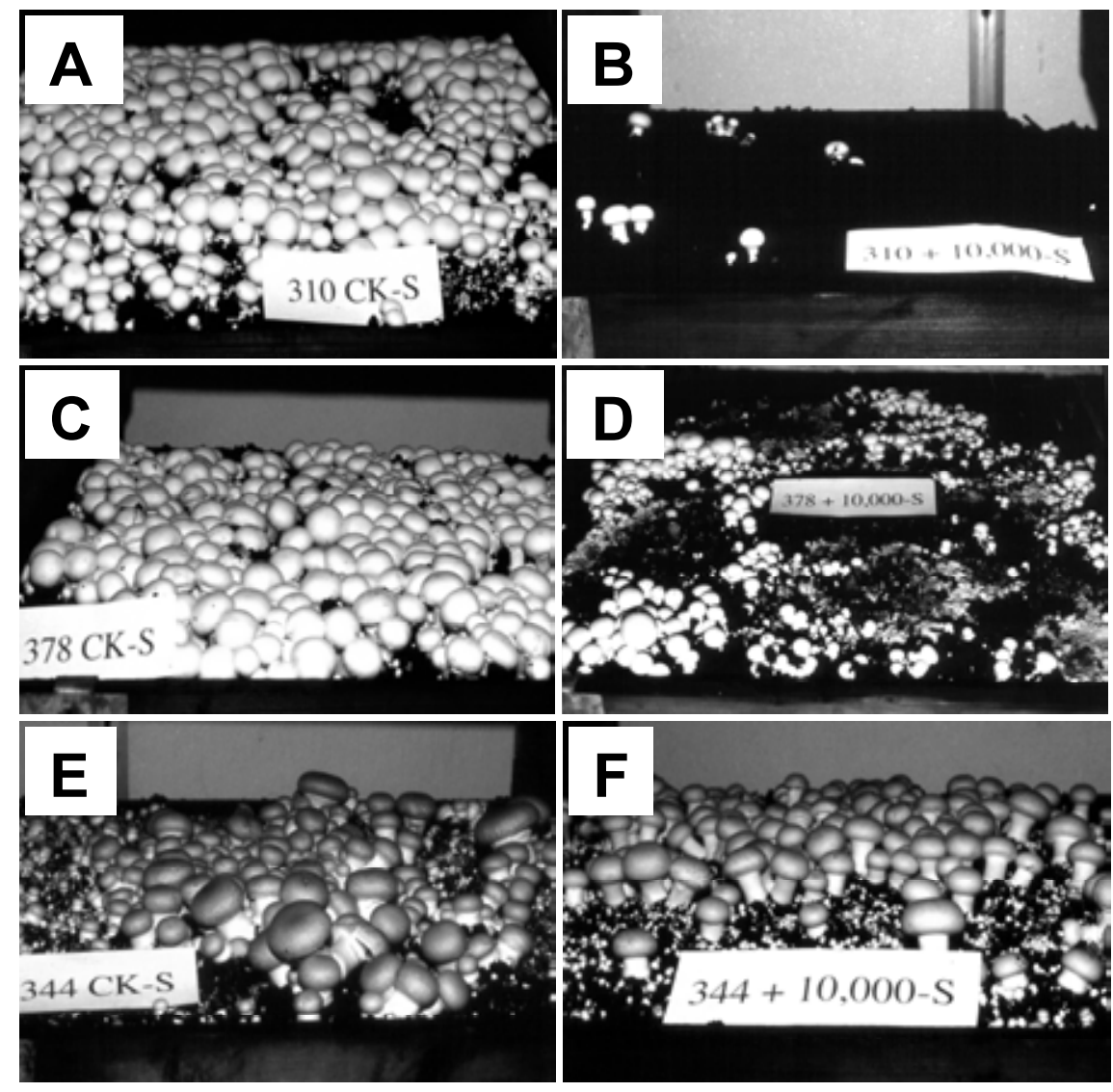

Fig. 2. Evaluation of mushroom strains based on yield response for resistance to Trichoderma aggressivum f. aggressivum. Shown are the $\mathbf{A}$, noninoculated and $\mathbf{B}$, inoculated pre-epidemic 310 white strain, $\mathbf{C}$, noninoculated and $\mathbf{D}$, inoculated post-epidemic U1 off-white strain, and $\mathbf{E}$, noninoculated and $\mathbf{F}$, inoculated post-epidemic 344 brown strain. Compost in each tray was mixed with $150 \mathrm{~g}$ of spawn that had been treated with $1 \mathrm{ml}$ of water containing either 0 (noninoculated) or $1 \times 10^{4}$ spores of T. aggressivum f. aggressivum (inoculated). The first break of mushrooms in the cropping cycle from compost amended with the time-released supplement SpawnMate IISE is shown.

an ability to protect the grain from green mold, perhaps through the production of metabolites that inhibit or stimulate $T$. aggressivum $\mathrm{f}$. aggressivum. Tokimoto and Komatsu (27) suggested that resistance in shiitake mushrooms was related to the production of antifungal compounds. In $A$. bisporus, metabolites stimulated the growth of $T$. aggressivum f. europaeum, while inhibiting other Trichoderma genotypes (11). Apart from these examples, the mechanism of green mold resistance has not been elucidated.

Perhaps one of the most practical implications of our study is the discovery of a positive correlation between the resistance of a mushroom strain based on crop loss analysis and the ability of the strain to protect the spawn substrate from colonization by the pathogen. For example, the post-epidemic brown strain displayed the highest resistance in cropping trials and was most resistant to green mold invasion of the spawn, while spawn of the preepidemic white strain, which had the highest susceptibility based on crop loss, was among the most vulnerable to attack. Once again, a rapid and encompassing colonization of the spawn would support an earlier and more extensive development of green mold in the production bed, thereby leading to greater yield loss.

Based solely on the results of the grain protection assay, we would predict the preepidemic white and cream strains to have a similar level of disease resistance. However, the grain test does not offer the level of resolution afforded by a crop loss assessment. We could not discern the small difference in resistance reported for the post-epidemic white and off-white hybrids (1), although a comparable resistance rating has been suggested (16). Regardless, the grain assay might find application in breeding programs, in which mushroom germ plasm could be screened in the laboratory for disease resistance.

\section{ACKNOWLEDGMENTS}

This work was supported by grants from the Pennsylvania Department of Agriculture (No. ME 445101) and the Mushroom Industry Farmerbased Applied Research Program.

\section{LITERATURE CITED}

1. Anderson, M. G., Beyer, D. M., and Wuest, P. J. 2001. Yield comparison of hybrid Agaricus mushroom strains as a measure of resistance to Trichoderma green mold. Plant Dis. 85:731-734.

2. Castle, A., Speranzini, D., Rghei, N., Alm, G., Rinker, D., and Bissett, J. 1998. Morphologi- cal and molecular identification of Trichoderma isolates on North American mushroom farms. Appl. Environ. Microbiol. 64:133-137.

3. Chang, S. T. 1999. World production of cultivated and medicinal mushrooms in 1997 with emphasis on Lentinus edodes (Berk.) Sing. in China. Int. J. Med. Mushrooms 1:291-300.

4. Chen, X., Romaine, C. P., Ospina-Giraldo, M D., and Royse, D. J. 1999. A PCR-based test for the identification of Trichoderma harzianum biotypes 2 and 4 inciting the worldwide green mold epidemic in cultivated $\mathrm{Aga}$ ricus bisporus. Appl. Microbiol. Biotechnol. 52:246-250.

5. Chen, X., Romaine, C. P., Tan, Q., Schlagnhaufer, B., Ospina-Giraldo, M. D., Royse, D J., and Huff, D. R. 1999. PCR-based genotyping of epidemic and preepidemic Trichoderma isolates associated with green mold of Agaricus bisporus. Appl. Environ. Microbiol. 65:2674-2678.

6. Economic Research Service. 2002. Vegetables and Melons Yearbook, Summary. United States Department of Agriculture. Online, publication ERS-VGS-2002s

7. Fletcher, J. T. 1997. Mushroom spawn and the development of Trichoderma compost mold. Mushroom News 45(8):6-11.

8. Fritsche, G., and Sonnenberg, A. S. M. 1988 Mushroom strains. Pages 101-123 in: The Cultivation of Mushrooms. L. J. L. D. van Griensven, ed. Interlingua T.T.I. Ltd., England.

9. Grogan, H. M., Noble, R., Gaze, R. H., and Fletcher, J. T. 1997. Compost inoculation and control of Trichoderma harzianum, a weed mould of mushroom cultivation. Mushroom News 45(4):29-36.

10. Harvey, C. L., Wuest, P. J., and Schisler, L. C. 1982. Diseases, weed molds, and indicator molds and abnormalities of the commercia mushroom. Pages 19-33 in: Penn State Handbook for Commercial Mushroom Growers. The Pennsylvania State University, University Park.

11. Mumpuni, A., Sharma, H. S. S., and Brown, A. E. 1998. Effects of metabolites produced by Trichoderma harzianum biotypes and Agaricus bisporus on their respective growth radii in culture. Appl. Environ. Microbiol. 64:5053-5056.

12. Muthumeenakshi, S., Mills, P. R., Brown, A. E., and Seaby, D. A. 1994. Intraspecific molecular variation among Trichoderma harzianum isolates colonizing mushroom compost in the British Isles. Microbiology 140:769-777.

13. National Agricultural Statistics Service. 2002. Mushrooms. United States Department of Ag riculture. Online, publication Vg 2-1-2 (8-02)

14. Ospina-Giraldo, M. D., Royse, D. J., Thon, M. R., Chen, X., and Romaine, C. P. 1998 Phylogenetic relationships of Trichoderma harzianum causing mushroom green mold in Europe and North America to other species of Trichoderma from worldwide sources. Mycologia 90:76-81.

15. Rinker, D. L., and Alm, G. 1997. Effect of supplementation at spawning or casing on the expression of Trichoderma harzianum in commercial mushroom production. Mushroom News: Sci. Technol. 45(11):6-11.

16. Rinker, D. L., and Alm, G. 1997. Investigations of factors influencing the expression of green mould. Mushroom World 8(2):25-29.

17. Rinker, D. L., and Alm, G. 1998. Effectiveness of benomyl-coated spawn against green mold disease. Mushroom World 9(1):15-20.

18. Romaine, C. P., Chen, X., Ospina-Giraldo, M D., and Royse, D. J. 1999. Phylogenetic analysis of Trichoderma spp. associated with green mold on Agaricus bisporus using a sequence in beta-tubulin gene 1. Pages 116-124 
in: Mushroom Biology and Mushroom Product. A. Broderick, ed. Proc. 3rd International Conference, Sydney, Australia.

19. Romaine, C. P., and Schlagnhaufer, B. 1992. Characteristics of a hydrated, alginate-based delivery system for cultivation of the button mushroom. Appl. Environ. Microbiol. 58:3060-3066.

20. Royse, D. J., and Romaine, C. P. 2003. Spawn application of fungicides for control of Trichoderma green mold of mushrooms, 2002. Fungic. Nematicide Tests. In press.

21. Samuels, G. J., Dodd, S. L., Gams, W., Castlebury, L. A., and Petrini, O. 2002. Tricho- derma species associated with the green mold epidemic of commercially grown Agaricus bisporus. Mycologia 94:146-170.

22. SAS Institute. 1996. JMP start statistics. SAS Institute Statistical Analysis System, Cary, NC.

23. Seaby, D. A. 1987. Infection of mushroom compost by Trichoderma species. Mushroom J. 179:355-361.

24. Seaby, D. A. 1996. Differentiation of Trichoderma taxa associated with mushroom production. Plant Pathol. 45:905-912.

25. Sinden, J., and Hauser, E. 1953. Nature and control of three mildew diseases of mush- rooms in America. Mushroom Sci. 2:177-180.

26. Staunton, L. 1987. Trichoderma green mold in mushroom compost. Mushroom J. 179:362363.

27. Tokimoto, K., and Komatsu, M. 1995. Selection and breeding of shiitake strains resistan to Trichoderma spp. Can. J. Bot. 73(S1): S962-S966.

28. Weaver, W. C., Kroger, M., and Kneebone, L. R. 1977. Comparative protein studies (kjeldahl, dye binding, amino acid analysis) of nine strains of Agaricus bisporus (Lange) Imbach. mushrooms. J. Food Sci. 42:364 366. 